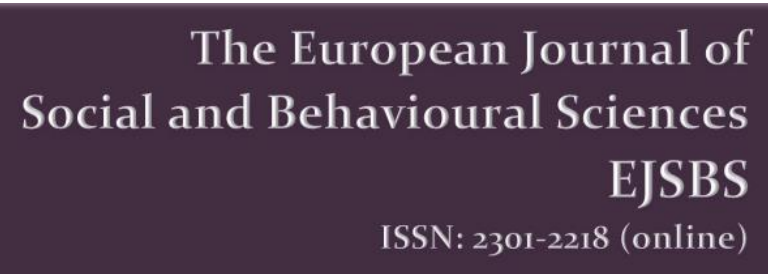

The European Journal of Social and Behavioural Sciences

EJSBS Volume II (e-ISSN: 2301-2218)

\title{
SELF-DETERMINATION FOR IRAQI'S TALENTED STUDENT
}

\author{
Taghavi Larijani Traneh ${ }^{\mathrm{a}}$, Ghadirian Fataneh ${ }^{\mathrm{b} *}$, Aliakbarzadeh Arani \\ Zahra $^{\mathrm{c}}$, Sharifi Nahiddokht ${ }^{\mathrm{d}}$, Noghani Fatemeh $^{\mathrm{d}}$, Faghihzadeh Soghrat $^{\mathrm{e}}$ \\ ${ }^{a}$ School of Nursing and Midwifery, Tehran university of Medical Sciences, Tehran, Iran \\ ${ }^{b}$ Department of nursing, School of Nursing and Midwifery, Tehran university of Medical Sciences, Tehran, Iran \\ ${ }^{c}$ School of Nursing and Midwifery, Kashan University of Medical Sciences, Kashan, Iran \\ ${ }^{d}$ School of Nursing and Midwifery, Tehran university of Medical Sciences, Tehran, Iran \\ ${ }^{e}$ School of Medical Sciences, university of Tarbiat Modares, Tehran, Iran
}

\begin{abstract}
This study conduct to assess the effectiveness of an educational Program based on Roy's adaptation theory for mothers of educable mentally retard children. The present study is quasiexperimental with single group pretest and posttest design. The sample includes 40 mothers with Educable mentally retarded children. A cognitive-behavioral program based on Roy's adaptation theory was hold. The program consisted of four weekly group sessions for two hours. Comparison four adaptation modes scores at pretest and post test showed significant differences in all modes of adaptation $(\mathrm{P}<0.001)$. The findings have identified that psycho educational program can effect on adaptation level in mothers of intellectual disabled children.
\end{abstract}

Keywords: Roy‘s adaptation theory, educable mentally retarded children, psycho educational program

(C) 2012 Published by C-crcs. Peer-review under responsibility of Editor(s) or Guest Editor(s) of the EJSBS.

${ }^{*}$ Corresponding author.

E-mail address: ghadirian.fataneh@gmail.com

doi: 10.15405/FutureAcademy/ejsbs(2301-2218).2012.2.9

This work is licensed under a Creative Commons Attribution-NonCommercial-NoDerivatives 4.0 International License. 
https://doi.org/10.15405/FutureAcademy/ejsbs(2301-2218).2012.2.9

eISSN: 2301-2218 / Corresponding Author: Ghadirian Fataneh

Selection \& Peer-review under responsibility of the Editors

\section{Introduction}

In a community, where the understanding of mentally retardation and the resources for people so affected is barely; parents can play a special role in the provision of care to their handicapped children, which is a stressful experience for many (Pearson \& Tim, 1993; Venters \& Wallander, 2001). When a family is aware of their child's health problem, they may experience a wild range of negative emotions and stressors that can significantly disrupt their coping mechanisms (Williams, Cullen, \& Barlow, 2005). In this situation, mothers of disabled children are at greatest risk of psychosocial distress and maladaptive behaviors (Eiser, 1993; Breslau, Staruch, \& Mortimer, 1982; Gonyea,1995). They suffer the emotional crisis; they are faced with the daily care and continuing dependency, and they must assume responsibility for the child's need (Shokoohi-Yekta, Zamania, \& Ahmadi, 2011). They may encountered a large number of reactions: chronic sorrow, loss of selfesteem, anxiety, guilt feeling, denial, mourning, hostility, anger, rejection, frustration, helplessness, shame, and disorganization of personality (Silvers, Bauman \& Ireys, 1995; Shokoohi-Yekta, Zamania, \& Ahmadi, 2011; Dahlen \& Martin, 2005; Perlis, Smoller, Fava, Rosenbaum \& et al., 2004).

Disparity between the children desired by the mother and the actual child results to psychological disadjustment and maladaptive process (Shokoohi-Yekta, Zamania, \& Ahmadi, 2011). These reactions could in fact affect the quality of mother's life (Cecilia, Cecilia \& Li-Tsang, 2003). Florian and Findler stressed on the importance of improving parental coping ability (Barlow, Wright, Shaw, Luqmani, \& Wyness, 2002). A study of 365 mothers concluded that interventions promoting skill building 
https://doi.org/10.15405/FutureAcademy/ejsbs(2301-2218).2012.2.9

eISSN: 2301-2218 / Corresponding Author: Ghadirian Fataneh

Selection \& Peer-review under responsibility of the Editors

and emotional validation could be reduced distress of the mothers with handicapped children (Silvers, Bauman, \& Ireys, 1995). Mobilizing these mothers to cope with their child's retardation needs professional help (Shokoohi-Yekta, Zamania, \& Ahmadi, 2011). Teaching some skills such as parenting strategies and emotional control to parents will enhance parent's abilities to deal effectively with problematic behaviors of children and to control their anger and solve conflicts (Shokoohi-Yekta, Zamania, \& Ahmadi, 2011).

Education is an important factor to overcome the tension that produced by any situation and can be considered as an adjusting factor (Shokoohi-Yekta, Zamania, \& Ahmadi, 2011). Having a higher level of education will increase the resources and the strengths of parents to manage challenging situations, and enable them to adapt (Menaghan \& Parcell, 1991). Theoretical models of stress suggest that cognitive appraisal and coping mechanisms may play a mediating role in the stress process (Barlow, Powell, \& Gilchrist, 2006). Roy's adaptation model is one of the most important models in nursing. According to model, person as an adaptive system is in constant interaction with the changing environment. To respond positively to environmental changes, the person must adapt. In this theory, the person is conceptualized as having four modes of adaptation: physiologic, self-concept, role function, and interdependence relations. Roy has defined health or wellness as "a process of responding positively to environmental changes that are called stressors" (Fawcett, 1993). 
https://doi.org/10.15405/FutureAcademy/ejsbs(2301-2218).2012.2.9

eISSN: 2301-2218 / Corresponding Author: Ghadirian Fataneh

Selection \& Peer-review under responsibility of the Editors

\section{Problem Statement}

Few studies have taken place about adaptation in parents of mentally retarded children based on adaptation theory of Roy, Ays (1993) showed significant correlations among coping patterns and some variables in mothers of mentally retarded child such as: educational level, race, family income, family size, and so on. He suggested that mother's education is necessary, especially in lower educational level (Ays, 1993). Also Moor (2005) used Roy‘s theory for assessing life experiences in mothers of sever cerebral palsy children. His qualitative findings describe social experiences and role function changes in these mothers (Moore, 2005). In Iran, few studies are found which have investigated the effects of an interventional program based on Roy`s adaptation theory in mothers with mentally retarded children.

\section{Research Questions}

Is educational program based on Roy's adaptation theory effective for mothers of educable mentally retard children?

\section{Purpose of the Study}

This study conduct to assess the effectiveness of an educational Program based on Roy's adaptation theory for mothers of educable mentally retard children.

\section{Research Methods}

The present study is quasi-experimental with single group pre test and post test design. The sample includes 40 mothers of Educable mentally retarded children which were students of exceptional school in Aranvabidgol. Sampling was randomly and 
https://doi.org/10.15405/FutureAcademy/ejsbs(2301-2218).2012.2.9

eISSN: 2301-2218 / Corresponding Author: Ghadirian Fataneh

Selection \& Peer-review under responsibility of the Editors

based on Poasson model. Inclusion criteria for mothers include: having an educable mentally retarded child between 6-17 years, not having any mental disorder, having ability to read and write at least. Not having participation in 2 sessions of educational course at least was considered as exclusion criteria. Next to giving informant consent, samples participated to interventional program.

The program consisted of four weekly group sessions for two hours. A workshop developed based on Roy`s adaptation theory. It is a cognitive-behavioral program that designed for promoting adaptation modes in these mothers. It has four major components: Physiologic needs, self-concept, role function, and interdependence relations. During this program, clients go through some cognitive changes, and skills such as stress management, problem solving, and role playing used to increase skills of psychological adjustment. This program provides an opportunity for review thoughts, feelings and roles for mothers. Therefore, it result to give mothers time to ask questions, ventilate feelings, and to enhance ability to recognize, evaluate and adapt to reality that is often significantly impaired. During 2-4 weeks after intervention, samples followed up by telenursing method.

Two questionnaires were used to assess the efficacy of program. 1) Demographic questionnaire: It contains 21 biographic items and relevant factors that can have effects on adaptation that comprise two parts: demographic mother's characteristics and demographic child's characteristics. 2) Adaptation Modes Questionnaire (AMQ):

This questionnaire was developed based on study of books, articles, relevant scales and questionnaires and interview with mothers who have children with special needs children. The AMQ with 50 items in Likert scale has four subscales: 1. 
https://doi.org/10.15405/FutureAcademy/ejsbs(2301-2218).2012.2.9

eISSN: 2301-2218 / Corresponding Author: Ghadirian Fataneh

Selection \& Peer-review under responsibility of the Editors

Physiologic mode, 2. Self-concept mode, 3. Role play mode, and 4. Interdependence mode. Within the first subscale, exercise and rest activities, nutrition habits, elimination patterns and sleep patterns and problems related to will be assessed. Second subscale assess the physical self, moral-ethical self, self-consistency, selfideal and expectancy and self- esteem. The third subscale comprises three subcategories: items about primary roles, developmental roles and contemporary roles. The last subscale assesses social integrity that includes dependent behaviors and independent behaviors. In a pilot study, the reliability using test-retest procedure after a week, for subscale of physiologic mode was $\% 84$, for self-concept mode $\% 84$, for role play mode $\% 97$, and for interdependence mode $\% 72$. In a sample of 40 mothers, the internal consistency calculated using Chronbach alpha was 0.91.

Participants completed this questionnaire before workshops as pre-test and 4-6 weeks after the end of fourth sessions, as post-test.

\section{Findings}

Data were analyzed using the statistics package for social scientists (SPSS) version 16. Descriptive statistic used for demonstrating Demographic and baseline characteristics of samples such as: mean and standard deviation scores. To determine differences between adaptation modes scores at pre and posttest used paired T test.

Exact Fisher test were used to assess whether total adaptation level were associated with any demographic variables. A significance level of $\% 5$ was used throughout. 
https://doi.org/10.15405/FutureAcademy/ejsbs(2301-2218).2012.2.9

eISSN: 2301-2218 / Corresponding Author: Ghadirian Fataneh

Selection \& Peer-review under responsibility of the Editors

\subsection{Demographic characteristics}

Fourteen mothers between the age of 25 and $35(\mathrm{M}=30, \mathrm{SD}=5)$ returned questionnaires. Majority of the participants were householders (\%90) and educational level of them were elementary (\%77.5). $67.5 \%$ of mothers had 2 children that majority of them their mentally retarded child was the first (\%37.5) and male (\%52.5). $40 \%$ Percent of mothers had medical conditions and $27 \%$ of mothers were taking medication. $35 \%$ of mothers didn't know exact cause of mental disability in their children.

\subsection{Adaptation modes and comparisons}

All the dependent variables were normally distributed. Finally, sum of the four adaptation modes scores calculated as total adaptation score and then ranked to three subgroups: desirable, relative desirable and undesirable.

Comparison four adaptation modes scores at pretest and post test showed significant differences in all modes (see table1). Results of correlation between total adaptation level and each of demographic variables scores showed significant differences with two variables: the time of understanding child's diagnosed by mothers $(\mathrm{P}=0.02)$ and the grade of birth in mentally retarded child $(\mathrm{P}=0.05)$ (see table2, 3). 
https://doi.org/10.15405/FutureAcademy/ejsbs(2301-2218).2012.2.9

eISSN: 2301-2218 / Corresponding Author: Ghadirian Fataneh

Selection \& Peer-review under responsibility of the Editors

Table 1. Means (Standard deviations) on study variables at baseline and 4-6 weeks follow-up

\begin{tabular}{|c|c|c|c|c|}
\hline & Baseline & Change scores & $t(d f)$ & P-value \\
\hline $\begin{array}{l}\text { Physiologic mode } \\
\text { Mean (SD) } \\
\text { (Range 0-51) }\end{array}$ & $25.4(5.71)$ & $28.8(4.95)$ & $6.03(39)$ & $<0.001$ \\
\hline $\begin{array}{l}\text { Self-concept mode } \\
\text { Mean (SD) } \\
\text { (Range 0-54) }\end{array}$ & $29.95(7.6)$ & $33.22(7.18)$ & 5.69 (39) & $<0.001$ \\
\hline $\begin{array}{l}\text { Role play mode } \\
\text { Mean (SD) } \\
\text { (Range } 0-27)\end{array}$ & $10.08(2.63)$ & $11.65(3.29)$ & 3.81 (39) & $<0.001$ \\
\hline $\begin{array}{l}\text { Interdependency mode } \\
\text { Mean (SD) } \\
\text { (Range 0-18) }\end{array}$ & $14.88(5.28)$ & $18.90(5.44)$ & $5.81(39)$ & $<0.001$ \\
\hline $\begin{array}{l}\text { Total adaptation } \\
\text { Mean (SD) } \\
\text { (Range } 0-150)\end{array}$ & $80.30(16.42)$ & $92.50(15.17)$ & $8.22(39)$ & $<0.001$ \\
\hline
\end{tabular}


Table 2. Frequency and Percentages of total Adaptation levels according to some mother's characteristics

\begin{tabular}{|c|c|c|c|c|}
\hline & Desirable & $\begin{array}{c}\text { Relative } \\
\text { desirable }\end{array}$ & Undesirable & $\mathbf{F}(\mathbf{d f})$ \\
\hline & $\begin{array}{c}\mathbf{n} \\
(\%)\end{array}$ & $\begin{array}{c}\mathbf{n} \\
(\%) \\
\end{array}$ & $\begin{array}{c}\mathbf{n} \\
(\%)\end{array}$ & P-value \\
\hline \multicolumn{5}{|l|}{ Age (years) } \\
\hline $25-35$ & $0(0)$ & $17(42.5)$ & $1(2.5)$ & $1.01(4)$ \\
\hline $35-45$ & $0(0)$ & $11(27.5)$ & $2(5)$ & 0.94 \\
\hline $45 \geq$ & $1(2.5)$ & $7(17.5)$ & $1(2.5)$ & .247 \\
\hline \multicolumn{5}{|l|}{ Number of children } \\
\hline $1-3$ & $1(2.5)$ & $24(60)$ & $2(5)$ & $0.64(2)$ \\
\hline$\geq 3$ & $0(0)$ & $11(27.5)$ & $2(5)$ & 0.74 \\
\hline \multicolumn{5}{|l|}{ Educational Level } \\
\hline Elementary & $1(2.5)$ & $26(65)$ & $4(10)$ & $3.07(4)$ \\
\hline Diploma & $0(0)$ & $8(20)$ & $0(0)$ & 0.63 \\
\hline Academic & $0(0)$ & $1(2.5)$ & $0(0)$ & \\
\hline \multicolumn{5}{|l|}{ Occupation } \\
\hline Employment & $1(2.5)$ & $3(7.5)$ & $0(0)$ & $1.91(2)$ \\
\hline Unemployment & $0(0)$ & $32(80)$ & $4(10)$ & 0.41 \\
\hline \multicolumn{5}{|l|}{ Family Income } \\
\hline Inadequate & $0(0)$ & $4(10)$ & $2(5)$ & $5.12(4)$ \\
\hline Relative Adequate & $0(0)$ & $20(50)$ & $2(5)$ & 0.25 \\
\hline Adequate & $1(2.5)$ & $11(27.5)$ & $0(0)$ & \\
\hline \multicolumn{5}{|c|}{$\begin{array}{l}\text { Time of Knowing child's } \\
\text { diagnose (months after } \\
\text { birth) }\end{array}$} \\
\hline $1-15$ & $0(0)$ & $20(50)$ & $3(7.5)$ & $9.62(4)$ \\
\hline $15-30$ & $0(0)$ & $4(10)$ & $0(0)$ & 0.02 \\
\hline $30-40$ & $1(2.5)$ & $11(27.5)$ & $1(2.5)$ & \\
\hline
\end{tabular}


Table 3. Frequency and Percentages of total Adaptation levels according to some child's characteristics

\begin{tabular}{|c|c|c|c|c|}
\hline & Desirable & $\begin{array}{l}\text { Relative } \\
\text { desirable }\end{array}$ & Undesirable & $\mathbf{F}(\mathbf{d f})$ \\
\hline & $\begin{array}{c}n \\
(\%) \\
\end{array}$ & $\begin{array}{c}\mathbf{n} \\
(\%) \\
\end{array}$ & $\begin{array}{c}n \\
(\%) \\
\end{array}$ & P-value \\
\hline \multicolumn{5}{|l|}{ Grade of child's birth } \\
\hline $1 \mathrm{st}$ & $1(2.5)$ & $14(35)$ & $0(0)$ & $9.23(4)$ \\
\hline 2 nd & $0(0)$ & $11(27.5)$ & $0(0)$ & 0.05 \\
\hline Others & 0.05 & $10(25)$ & $4(10)$ & \\
\hline \multicolumn{5}{|l|}{ Age } \\
\hline $5-10$ & $0(0)$ & $18(45)$ & $0(0)$ & $5.9(4)$ \\
\hline $10-15$ & $1(2.5)$ & $13(32.5)$ & $2(5)$ & 0.19 \\
\hline $15-20$ & $0(0)$ & $4(10)$ & $2(5)$ & \\
\hline \multicolumn{5}{|l|}{$\operatorname{Sex}$} \\
\hline Female & $0(0)$ & $17(42.5)$ & $2(5)$ & $2.96(2)$ \\
\hline Male & $1(2.5)$ & $18(45)$ & $2(5)$ & 0.27 \\
\hline \multicolumn{5}{|l|}{$\begin{array}{l}\text { Severity of mentally } \\
\text { retardation }\end{array}$} \\
\hline Mild & $0(0)$ & $19(47.5)$ & $1(2.5)$ & $0.82(2)$ \\
\hline Moderate & $1(2.5)$ & $16(40)$ & $3(7.5)$ & 0.66 \\
\hline \multicolumn{5}{|l|}{ Cause } \\
\hline Genetic & $0(0)$ & $8(20)$ & $0(0)$ & $10.29(10)$ \\
\hline Damage in Prenatal & $0(0)$ & $6(15)$ & $1(2.5)$ & 0.37 \\
\hline Damage in Delivery & $0(0)$ & $2(5)$ & $1(2.5)$ & \\
\hline Damage after birth & $1(2.5)$ & $6(15)$ & $0(0)$ & \\
\hline Others & $0(0)$ & $1(2.5)$ & $0(0)$ & \\
\hline Don't Know & $0(0)$ & $12(30)$ & $2(5)$ & \\
\hline
\end{tabular}


https://doi.org/10.15405/FutureAcademy/ejsbs(2301-2218).2012.2.9

eISSN: 2301-2218 / Corresponding Author: Ghadirian Fataneh

Selection \& Peer-review under responsibility of the Editors

\section{Conclusions}

The results of this study suggest that the psycho educational program based on Roy's adaptation theory may be an effective way of improving mother's adaptation level. Further studies are needed to determine whether these improvements are maintained over time and to examine in greater sample size and with a control group.

Findings of this study showed that mothers of mentally handicapped children have a lower socio-economic status, that it is congruent with several other studies (Baker, McIntyre, Blacher, Crnic, Edelbrock, \& Low, 2003; Emerson, 2003; Khamis, 2007; Pearson \& Tim, 1993; Shokoohi-Yekta, Zamania, Ahmadi, 2011; Zigler, 1976). Emerson, et al. (2004) stated that socio-economic deprivations could result to increase psychological distress of the caregivers of these children (Emerson, 2003). Pearson et al. (1993) stated that mothers with handicapped children has less education than mothers in control group, but necessarily little education doesn't mean little education is equal to low intelligence. The lower educational level was, the higher the experienced stress (Pearson \& Tim, 1993). Shokoohi-Yekta et al. (2011) showed that there is a significant difference between anger in mothers with different levels of education (Shokoohi-Yekta, Zamania, \& Ahmadi, 2011). Thomas (1989) stated that anger in males and females with lower level of education is higher (Thomas, 2001). Perhaps we can say educated people are more successful in controlling their negative emotions that have negative impacts on their mental and physical health. Findings of Khamis (2008) haven't shown any relation between parent's education and parent's distress or stress (Khamis , 2007). 
In other studies founded some parental characteristics such as employment and family income predict parental stress (Baker, McIntyre, Blacher, Crnic, Edelbrock, \& Low, 2003; Emerson, 2003; Khamis, 2007) and quality of life in them (Jin-Ding, Jung, Chia-Feng, Shang-Wei, Lan-Ping, Ching-Hui, Mei-Hua, Sheng-Ru, Cordia , Jia- Ling , 2009). Perhaps enabling mothers to participate more fully in activities outside at the home and employment, protect mothers from the risk of psychological distress (Barlow, Powell, \& Gilchrist, 2006; Breslau, Staruch, \& Mortimer, 1982). Being employed and having relationship whit social networks outside their homes have many benefits for these mothers such as: helping family income; receiving further social support and emotional support; and promoting their knowledge and skills for better situation management. Employed mothers have better personal and family resources; they have a better social prestige and social support. Job has proven to have effects on mental health. Pearson stated that the mothers of handicapped children have less scores in social support from their significant others, in comparison with mothers in the control group $(\mathrm{P}=0.008)$. They also receive less emotional and instrumental supports, especially emotional support $(\mathrm{P}=0.008)$ (Pearson \& Tim, 1993). The more support mothers received, the less stress they experienced. Research showed that support has two major effects: overall well-being and protecting one from the potentially pathogenic influence of stressful life events (Cohen \& Willis, 1985). Perhaps we can say social acceptance of the mentally handicapped children has an important role at receiving social recognition and empathy from society by mothers of these children. Studies indicate that as the mentally retarded children grow, their parents might feel pressure from society. Thus, they limit their social networks (Kazak \& Marvin, 1984; Kazak \& Wilcox, 1984). Some parents also avoid their relatives and 
https://doi.org/10.15405/FutureAcademy/ejsbs(2301-2218).2012.2.9

eISSN: 2301-2218 / Corresponding Author: Ghadirian Fataneh

Selection \& Peer-review under responsibility of the Editors

friends because of fearing misunderstandings towards children's needs (Ayrault, 2001). Therefore, attitudes of parents, rather than their children's level of disabilities, seem to be the main determinant for active social participation. Of course, this limitation in their social network is likely to deal with their feeling of depression and disappointment (Li-Tsang, Yau, \& Yuen, 2001). Some Studies showed proportions at risk of clinically anxious and depressed moods were significantly greater than published norms (Barlow, Powell, \& Gilchrist, 2006; Crawford, Henry, Crombie, \& Taylor, 2001).

Results of this study showed significant correlation to time of knowing child's diagnose and mother's adaptation level. $50 \%$ of mothers in this study had known their child's diagnose 1-15 months after the birth of disabled child. Miller (1968) stated three stages of parental adjustment after the understanding diagnose. The most common early reaction to tragedy is shock, disorganization and denial. In this stage people have very little energy for coping effectively with the environment and carrying on. Following the first stage, adjustment starts. During this stage parents suffer from chronic sorrow, and partly accept and partly deny the retardation. The final step in adjustment is orientation. In this stage, people begin to function more effectively and more realistically.

Results of this study didn't show significant relation between total adaptation level and age of mentally retarded children $(\mathrm{P}=0.19)$. In other studies, of the children characteristics, age of the children is significantly associated with parental distress and stress (Baker, McIntyre, Blacher, Crnic, Edelbrock, \& Low, 2003; Emerson, 2003; Khamis, 2007). Lin et al. (2009) showed slightly correlation between age of 
https://doi.org/10.15405/FutureAcademy/ejsbs(2301-2218).2012.2.9

eISSN: 2301-2218 / Corresponding Author: Ghadirian Fataneh

Selection \& Peer-review under responsibility of the Editors

children and physical capacity $(\mathrm{p}=0.01)$ and psychological well-being mean scores $(\mathrm{P}=0.04)$ of the caregivers of the intellectual disabled children and adolescents.

Findings of this study support from main objective of this research and show the effectiveness of psycho educational program based on Roy's theory on adaptation modes for mothers of educable mentally retarded children. Study of Williams, Cullen and Barlow showed that the training and support program in an 8-week in which careers of children with disabilities could result in higher levels of self-efficacy and psychological well-being $(\mathrm{P}<0.001, \mathrm{P}<0.001)$. Cullen and Barlow also stated that parents of children with autism immediately after the program reported improvement in self- efficacy, anxious and depressed moods and perceptions of their own health (Cullen \& Barlow, 2002). Feber and Ryckman (1965) suggested that help to the establishment of priorities in family life enabled the family to cope with the variety of problems which face to it.

There were several limitations to this study. Firstly, our group size was modest, but similar to that of Shokoohi-yekta and et al. (2010) who investigated instructing anger management skills in 46 mothers of mentally retarded children. Also, the association between psycho educational program and adaptation level is complex. Lastly, having single group without a control group has limited interpreting findings.

The findings have identified that psycho educational program based on adaptation theory of Roy can effect on physiologic, self-esteem, role function and interdependence dimensions and wholly adaptation level in mothers of intellectual disabled children. 
Further research is required in order to gain greater insight into the adaptive modes of these mothers. It is suggested that future researches could also examine the effectiveness of this program on mothers in two groups and with a greater sample size.

\section{Acknowledgements}

The authors declare that there is no conflict of interest. This research was financially supported by Tehran University of Medical Sciences and Health Services. The authors would like to thanks to research director of Medical Sciences of Tehran, directors of nursing and midwifery faculty of Tehran University of Medical Sciences for their advice and guidance on the research design.

In addition, the authors want to acknowledge the kindness of all of the personnel of the exceptional children's school and all mothers who helped us to conduct this study.

\section{References}

Atkin, K. (2000). Adults with disabilities who reported excellent or good quality of life have established a balance of body, mind, and spirit. Evidence Based Nursing, 3, 31. https://doi.org/10.1136/ebn.3.1.31

Ayrault, E. W. (2001). Beyond a Physical Disability. The Person within - A Practical Guide. New York: The Continuum International Publishing Group.

Ays, H. (1993). Child- Family Characteristics and Coping Patterns of Indonesian Families with a mentally Retarded Child. Catholic university of American, D.N.SC, Doctoral Dissertation Research, 228.

Baker, B. L., McIntyre, L. L., Blacher, J., Crnic, K., Edelbrock, C., \& Low, C. (2003). Pre-school children with and without developmental delay: Behavior problems 
and parenting stress over time. Journal of Intellectual Disability Research, 47, 217-230. https://doi.org/10.1046/j.1365-2788.2003.00484.x

Barlow, J., Powell, L., \& Gilchrist, M. (2006). The influence of the training and support programme on the self-efficacy and psychological well-being of parents of children with disabilities: A controlled trial. Complementary Therapies in Clinical Practice, 12, 55- 63. https://doi.org/10.1016/j.ctcp.2005.02.005

Barlow, J. H., Wright, C. C., Shaw, K. L., Luqmani, R., \& Wyness, I. J. (2002). Maternal stressors, maternal wellbeing and children's wellbeing in the context of juvenile idiopathic arthritis. Early Child Dev Care, 172, 89-98. https://doi.org/10.1080/03004430210875

Breslau, N., Staruch, K., \& Mortimer, E. (1982). Psychological distress in mothers of disabled children. Am J Dis Children, 136, 682-686. https://doi.org/10.1001/archpedi.1982.03970440026007

Breslau, N., Staruch, K. S., \& Mortimer, J. E. A. (1982). Psychological distress in mothers of disabled children. Am J Disabled Child, 36, 682-686. https://doi.org/10.1001/archpedi.1982.03970440026007

Cecilia, Y. L, Cecilia, W., \& Ping, L. T. (2003). Quality of Life of Parents who have Children with Disabilities. Hong Kong Journal of Occupational Therapy, 13, 19-24. https://doi.org/10.1016/S1569-1861(09)70019-1

Cohen, S., \& Willis, S. T. (1985). Stress, social support and the buffering hypothesis. PsychoI. Bull, 98, 310-357. https://doi.org/10.1037/0033-2909.98.2.310

Crawford, J. R., Henry, J. D., Crombie, C., \& Taylor, E. P. (2001). Brief report: normative data for the HADS from a large non-clinical sample. $\mathrm{Br} J$ Clin Psycho, l40, 429-34. https://doi.org/10.1348/014466501163904

Cullen, L. A., \& Barlow, J. H. (2002). Kiss, cuddle and squeeze" : the experiences and meaning of touch among parents of children with autism attending a touch therapy programme. $J$ Child Health, 6(3), 171-81. https://doi.org/10.1177/136749350200600303

Cullen, L. A., \& Barlow, J. H. (2002). Parents' experiences of caring for children with autism and attending a touch therapy program. Child Care Pract, 8(1), 35-47. https://doi.org/10.1080/13575270220140452 
Dahlen, E. R., \& Martin, R. C. (2005). The experience, expression, and control of anger in perceived social support. Personality and Individual Differences, 39, 391-401. https://doi.org/10.1016/j.paid.2005.01.019

Eiser, C. (1993). Growing up with a chronic disease: the impact on children and their families. London: Jessica Kingsley Publishers Ltd.

Emerson, E. (2003). Mothers of Children and Adolescents with Intellectual Disability: Social and Economic Situation Mental Health Status and the Self-assessed Social and Psychological Impact of the Childs Difficulties. Intellect Disability, 47(5), 385-399. https://doi.org/10.1046/j.1365-2788.2003.00498.x

Farber, B., \& Ryckman, D. (1965). Effects of Severely Mentally Retarded Children on Family Relationships. Mental Retardation Abstracts, 2(1), 1-17.

Fawcett, J. (1993). Analysis and Evaluation of Nursing Theories. F. A. Davis Company.

Gonyea, J. G. (1995). Encyclopaedia of marriage and the family. New York, NY: Macmillan.

Jin-Ding, L., Jung, H., Chia-Feng, Y., Shang-Wei, H., Lan-Ping, L., Ching-Hui, L., Mei- Hua, C., Sheng-Ru, W., Cordia, M. C., \& Jia-Ling, W. (2009). Quality of life in caregivers of children and adolescents with intellectual disabilities: Use of WHOQOL- BREF survey. Research in Developmental Disabilities, 30, 1448-1458. https://doi.org/10.1016/j.ridd.2009.07.005

Kazak, A. E., \& Marvin, R. (1984). Differences, difficulties, and adaptation: stress and social networks in families with a handicapped child. Family Relations, 33, 67-77. https://doi.org/10.2307/584591

Kazak, A. E., \& Wilcox, B. L. (1984). The structure and function of social support networks in families with handicapped children. American Journal of Community Psychology, 12, 645-661. https://doi.org/10.1007/BF00922617

Khamis, V. (2007). Psychological distress among parents of children with mental retardation in the United Arab Emirates. Social Science \& Medicine, 64, 850 857. https://doi.org/10.1016/j.socscimed.2006.10.022

Li-Tsang, W. P. C., Yau, M. K. S., \& Yuen, H. K. (2001). Success in parenting children with developmental disabilities: some characteristics, attitudes and 
adaptive coping skills. British Journal of Developmental Disabilities, 47, 6171. https://doi.org/10.1179/096979501799155594

Matheny, A. P., \& Vernick, J. (1969). Parents of Mentally Retarded Child: Emotionally Overwhelmed or Informationally Deprived? The Journal of Pediatrics, 74(6), 953-959. https://doi.org/10.1016/S0022-3476(69)80231-3

Menaghan, E. G., \& Parcell, T. L. (1991). Determining of children family environments: The effect of maternal characteristics and current. Occupational and family conditions. Journal of Marriage and Family, 53, 417-431. https://doi.org/10.2307/352909

Miller, L. G. (1968). Toward a greater Understanding of the parents of the Mentally Retarded Child. The Journal of Pediatrics, 73(5), 699-705. https://doi.org/10.1016/S0022-3476(68)80175-1

Moore, L. A. (2005). The Lived Experience of Being a Mother of a Child with Sever Cerebral palsy, Ohio Medical College, Doctoral Dissertation.

Nihira, K., Edward, M., \& Mink, I. T. (1980). Home Environment and Family Adjustment and the Development of Mentally Retarded Children. Applied Research in Mental Retardation, 1, 5-24. https://doi.org/10.1016/02703092(80)90013-2

Pearson, V., \& Tim, W. L. (1993). The Relationship between Parenting Stress and Social Support in Others of Children with Learning Disabilities: A Chinese Experience. Sot. Sri. Med, 37(2), 261-214. https://doi.org/10.1016/02779536(93)90461-C

Perlis, R. H., Smoller, J. W., Fava, M., Rosenbaum, J. F., Nierenberg, A., \& Sachs, G. S. (2004). The prevalence and clinical correlates of anger attacks during depressive episodes in bipolar disorder. Journal of Affective Disorders, 79, 291295. https://doi.org/10.1016/S0165-0327(02)00451-2

Schneider, J. W., Gurucharri, L. M., Gutierrez, A. L., \& Gaebler-Spira, D. J. (2001). Health-related quality of life and functional outcome measures for children with cerebral palsy. Developmental Medicine \& Child Neurology, 43, 601-608. https://doi.org/10.1017/S0012162201001098

Shokoohi-Yekta, M., Behpajooh, A., Ghobari- Bonab, A., Zamani, N., \& Parand, A. (2010). Instructing anger management skills for mothers of mentally retarded 
children: effects on mother-child relationship. Procedia Social and Behavioral Sciences, 5, 1438-1441. https://doi.org/10.1016/j.sbspro.2010.07.303

Shokoohi-Yekta, M., Zamania, N., \& Ahmadi, A. (2011). Anger management training for mothers of mildly mentally retarded and slow learner children: effects on mother- child relationship. Procedia Social and Behavioral Sciences, 15, 722-726. https://doi.org/10.1016/j.sbspro.2011.03.172

Shokoohi-Yekta, M., Zamania, N., \& Ahmadi, A. (2010). Anger in mothers of children with disabilities: effects of occupation and level of education. Procedia Social and Behavioral Sciences, 15, 712-716. https://doi.org/10.1016/j.sbspro.2011.03.170

Silvers, E. J., Bauman, L. J., \& Ireys, H. (1995). Relationships of selfesteem and efficacy to psychological distress in mothers of children with chronic physical illness. Health Psychol, 14, 333-40. https://doi.org/10.1037/02786133.14.4.333

Thomas, S. P. (2001). Teaching healthy anger management. Perspectives in Psychiatric Care, 37, 41- 48. https://doi.org/10.1111/j.17446163.2001.tb00617.x

Venters Horton, T., \& Wallander, J. L. (2001). Hope and social support as resilience factors against psychological distress of mothers who care for children with chronic physical Conditions. Rehabil Psychol, 46, 382-99. https://doi.org/10.1037/0090-5550.46.4.382

Williams, H. L., Cullen, L., \& Barlow, J. H. (2005). The psychological well-being and self-efficacy of carers of children with disabilities following attendance on Simple Massage training and Support Programme: A 12-month comparison study of adherers and non-adherers. Complementary Therapies in Medicine, 13, 107-114. https://doi.org/10.1016/j.ctim.2005.03.007

Zigler, E. (1976). Men and Rrlurdution. Cambridge, UK: Cambridge University Press. 